\title{
Astaxanthin in the calanoid copepod Calanus helgolandicus: dynamics of esterification and vertical distribution in the German Bight, North Sea
}

\author{
Frank Sommer ${ }^{1, *}$, Cristian Agurto $^{2}$, Peter Henriksen ${ }^{3}$, Thomas Kiørboe ${ }^{1}$ \\ ${ }^{1}$ Danish Institute for Fisheries Research, Marine Ecology and Aquaculture, Kavalergården 6, 2920 Charlottenlund, Denmark \\ ${ }^{2}$ Leibniz-Institute for Marine Sciences, Marine Ecology, Düsternbrooker Weg 20, 24105 Kiel, Germany \\ ${ }^{3}$ National Environmental Research Institute, Marine Ecology, Frederiksborgvej 399, PO Box 358, 4000 Roskilde, Denmark
}

\begin{abstract}
Zooplankton synthesise astaxanthin, a carotenoid pigment believed to protect against high-energy irradiance, from precursors in their diet. Different patterns of astaxanthin vertical distribution would be expected from the benefits of photoprotection, the costs of visual predation and the availability of food. Despite a highly resolved sampling approach (4 $\mathrm{m}$ depth intervals), no clear pattern of vertical distribution or correlation with chlorophyll a concentrations was found for Calanus helgolandicus astaxanthin concentrations in the German Bight. This may be attributable to photochromatic adaptation in phytoplankton, diurnal rhythms of copepod grazing and, particularly, vertical migration. A $2 \times 2$ factorial (light $\times$ food) experiment showed that total astaxanthin concentrations in C. helgolandicus were entirely determined by the dynamics of esterified astaxanthin. As expected, the concentrations of astaxanthin esters decreased in starved individuals in the dark, while the combined presence of food and light resulted in an increase of esterified astaxanthin. Similar levels of esterified astaxanthin were maintained in both starving individuals exposed to light and feeding individuals in the dark. The latter implies that astaxanthin esterification is per se a process independent of light, although light exposure enhances it. It is proposed that the function of astaxanthin esters is to generally improve the antioxidant protection of storage lipids, also in situations where photoprotection is not required.
\end{abstract}

KEY WORDS: Astaxanthin $\cdot$ Carotenoids $\cdot$ Pigments $\cdot$ Photoprotection $\cdot$ Vertical migration

\section{INTRODUCTION}

Zooplankton synthesise astaxanthin, a carotenoid pigment, from precursors in their diet (Goodwin 1984). Chemically, it is found in the free (unesterified) form, as mono- and di-esters of fatty acids or bound to proteins forming carotenoproteins. Because of its strong antioxidant ability, astaxanthin is believed to protect zooplankton from photo-oxidative damage caused by high-energy irradiance (Hairston 1978). This view is supported by experimental studies showing the higher survival of intensely pigmented compared to transparent individuals exposed to ultraviolet (UV) or blue light (Hairston 1978, Ringelberg et al. 1984, Davenport et al.
2004). Furthermore, zooplankton have been shown to respond differentially to UV exposure, with lesspigmented species descending farther from the light source than more intensely pigmented ones (Rhode et al. 2001).

Studies on the vertical distribution of carotenoids in freshwater zooplankton are generally consistent with a photoprotective function, i.e. the more pigmented individuals occur closer to the surface (Hairston 1980, Byron 1982, Hansson 2000). In contrast, the more pigmented zooplankton in the sea are often found to occur deeper (Herring 1972) and to avoid the sea surface $(<6 \mathrm{~m})$ during the daytime (Hays et al. 1994). Thus, while the latter, marine results are consistent with pre- 
dictions of surface avoidance as a means of reducing the increased predation risk from visual predators (Hairston 1979, Luecke \& O'Brien 1981, Byron 1982), they are clearly difficult to bring in line with a photoprotective function of astaxanthin.

Here, we report on the vertical distribution of astaxanthin concentrations in the copepod Calanus helgolandicus in the German Bight, North Sea, during summer. We adopted a high-resolution sampling approach with sampling at $4 \mathrm{~m}$ depth intervals, given that blue and UV light is generally completely attenuated within the top 2 to $10 \mathrm{~m}$ in temperate coastal waters (Jerlov 1976, Kuhn et al. 1999). We expected one of the following: (1) a decrease is astaxanthin with increasing depth due to photoprotection, (2) an increase with increasing depth due to visual predation, (3) a 'trade-off', with lowest concentrations at intermediate depths, or (4) a positive relationship with phytoplankton biomass, since astaxanthin synthesis depends on the ingestion of precursor carotenoids. In addition, we performed an $2 \times 2$ factorial onboard experiment to test for the effects of food and light on the temporal dynamics of astaxanthin.

\section{MATERIALS AND METHODS}

Zooplankton were collected at 3 stations in the German Bight, North Sea, from 9 to 11 August 2004. The stations were sampled in the order: Stn $11\left(7^{\circ} 40^{\prime} \mathrm{E}\right.$, $\left.54^{\circ} 10^{\prime} \mathrm{N}\right)$ at $15: 00 \mathrm{~h}_{i} \operatorname{Stn} 22\left(7^{\circ} 00^{\prime} \mathrm{E}, 54^{\circ} 20^{\prime} \mathrm{N}\right)$ at 23:00 $\mathrm{h}_{\text {; }}$ and $\operatorname{Stn} 35\left(5^{\circ} 00^{\prime} \mathrm{E}, 54^{\circ} 40^{\prime} \mathrm{N}\right)$, at $01: 00 \mathrm{~h}$ and again at 13:00 h. Surface $(<0.5$ to $1 \mathrm{~m})$ and subsurface (4 to $28 \mathrm{~m}$ ) samples were collected with a Bongo net (310 $\mu \mathrm{m}$ mesh size) and a multiple opening-closing net (335 $\mu \mathrm{m}$ mesh size) at $4 \mathrm{~m}$ intervals, respectively. After sampling $(\sim 1.5 \mathrm{~h})$ and gut evacuation $(\sim 1 \mathrm{~h})$, zooplankton were collected on sieves $(\sim 1.5 \mathrm{~h})$ and subsequently stored in liquid nitrogen. Thus, the total time elapsed between sampling initiation and fixation was $\sim 4 \mathrm{~h}$.

An onboard experiment was conducted with copepods collected on 28 July 2005 at the chl a maximum $(\sim 42 \mathrm{~m})$ of a deep $(60 \mathrm{~m})$ station $\left(3^{\circ} 27^{\prime} \mathrm{E}, 56^{\circ} 39^{\prime} \mathrm{N}\right)$. The experimental design was $2 \times 2$ factorial, with food or no food addition crossed with light or no light exposure (4 treatments $\times 2$ replicates). Copepods were added to a total of 8 buckets $(20 \mathrm{l})$ containing either GF/F-filtered seawater or unfiltered seawater from the chl a maximum; 2 buckets of each group were covered with black foil or exposed to continuous white light provided by $2 \times 58 \mathrm{~W} / 30$ Osram $^{\mathrm{TM}}$ fluorescent lamps. The light intensity $\left(50 \mu \mathrm{mol} \mathrm{m}{ }^{-2} \mathrm{~s}^{-1}\right)$ was adjusted to that of the chl a maximum at noon. Gentle aeration was provided to all buckets to prevent phytoplankton from sinking. Zooplankton samples were taken at $0,4,12$ and $24 \mathrm{~h}$ after the onset of the experiment and immediately stored in liquid nitrogen.

In the laboratory, females and Stage 5 copepodites of Calanus helgolandicus were separated under a dissecting microscope and collected on small $(\sim 5 \times$ $10 \mathrm{~mm}$ ) pieces of GF/F filter. Generally, all available individuals of a sample (20 to 30 ) were pooled in order to obtain 1 measurement per depth interval. After selection, the copepodites were stored at $-80^{\circ} \mathrm{C}$ for $\sim 2$ mo until pigment analysis by high-performance liquid chromatography (HPLC). Re-freezing the samples after selection had no significant impact on the astaxanthin concentrations (Student's $t$-test, $\mathrm{n}=8, \mathrm{p}>0.4$ ).

Pigments were extracted by placing the filters into $5 \mathrm{ml}$ syringes capped with a $0.2 \mu \mathrm{m}$ filter, together with $1000 \mu \mathrm{l}$ acetone. For the onboard samples, $2 \mathrm{ml}$ syringes and $500 \mu \mathrm{l}$ acetone were used. After sonification $(\sim 10 \mathrm{~s})$ and extraction in the dark $\left(24 \mathrm{~h}\right.$ at $\left.-20^{\circ} \mathrm{C}\right)$, the copepod and filter-remains were removed by squeezing the extract through the filter. Aliquots $(100 \mu \mathrm{l})$ of the filtrate were measured in a Shimadzu HPLC-system equipped with an LC18 cartridge column $(25 \mathrm{~cm} \times 4.6 \mathrm{~mm} \times 5 \mu \mathrm{m})$ and a photodiode-array detector. The solvent system (Solvent A: $80 \%$ methanol, 20\% 0.5 M ammonium acetate; Solvent B: $90 \%$ acetronitril, $10 \%$ water; Solvent C: $100 \%$ ethylacetate) used the linear gradient 0 min: $100 \% \mathrm{~A}_{;} 2 \mathrm{~min}$ : $100 \%$ B 2.6 min: $85 \%$ B, $15 \%$ C; 15 min: $29 \%$ B, $71 \%$ C; 25 min: $100 \%$ B; 27 min: $100 \%$ A. Free astaxanthin and its esters ( 4 to 6 peaks) were identified by the retention time and/or absorption spectrum of commercially available astaxanthin (Sigma ${ }^{\mathrm{TM}}$ ).

Copepod dry weight (DW) was estimated from length measurements using length: DW regressions (Mauchline 1998). Chl a was determined spectrophotometrically from samples $(500 \mathrm{ml})$ extracted in $90 \%$ acetone $(24 \mathrm{~h})$.

Using the GLM procedure of SAS ${ }^{\mathrm{TM}}$, multivariate analysis was conducted with depth, station and time of sampling (day/night) as independent variables. Nonsignificant $(p>0.05)$ variables were removed in a backward, stepwise process. Regressions on timebased astaxanthin concentrations were performed using SigmaPlot ${ }^{\mathrm{TM}} 9.0$ software.

\section{RESULTS}

Calanus helgolandicus was found at all depth intervals of stations sampled at night, but was absent from the surface and deeper depth intervals in the daytime, particularly at Stn 11 (Fig. 1). Overall, the concentrations of astaxanthin were low $\left(<0.22 \mathrm{gg} \mathrm{mg}^{-1} \mathrm{DW}\right)$ and seemed unrelated with depth. However, multivariate analysis revealed a significant correlation of the total 

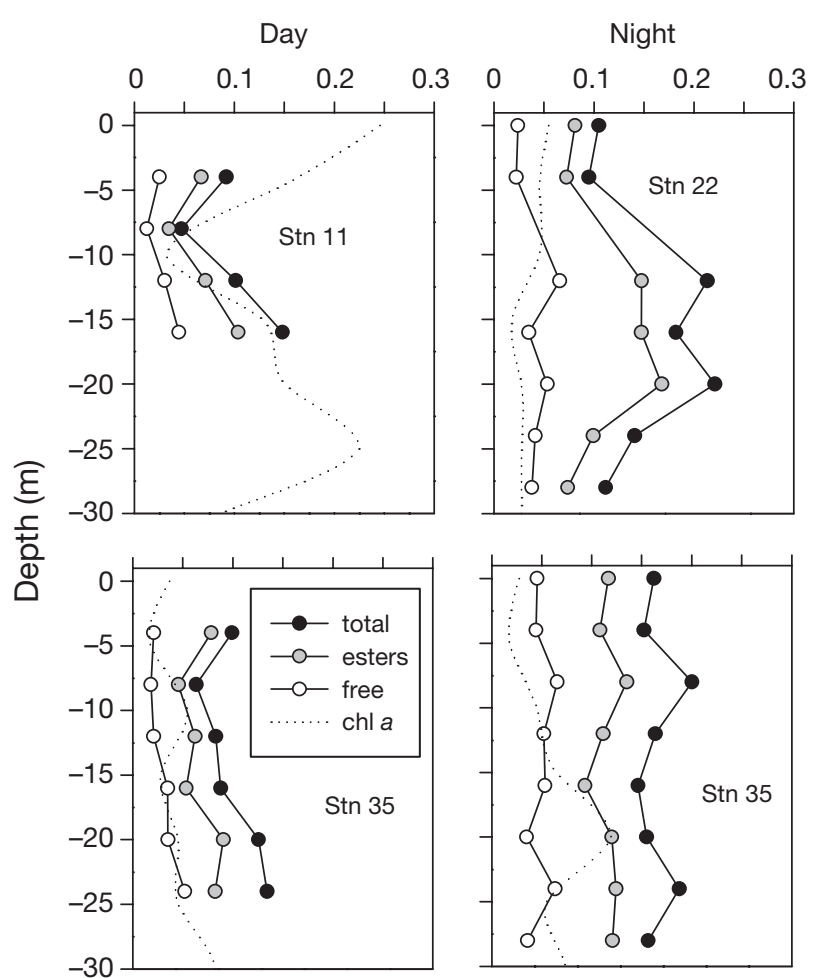

$\mu \mathrm{g}$ astaxanthin $\left(\mathrm{mg}^{-1} \mathrm{DW}\right)$ and $\mu \mathrm{g} \mathrm{chl} \mathrm{a} \mathrm{l}^{-1}(\mathrm{x} 10)$

Fig. 1. Calanus helgolandicus. Chl a and copepod astaxanthin concentrations as a function of depth. No astaxanthin data are available for the $8 \mathrm{~m}$ depth interval at Stn 22

and esterified astaxanthin concentrations with depth (Table 1). This was due to the somewhat lower concentrations at the 4 and $8 \mathrm{~m}$ depth intervals compared to the preceding surface and $4 \mathrm{~m}$ depth intervals, respectively.

Similarly, the vertical distribution of astaxanthin seemed unrelated with the vertical distribution of chl $a$, with the possible exception of Stn 11 (Fig. 1). Plotting total astaxanthin as a function of chl a yielded no significant correlation (Fig. 2). Instead it showed that

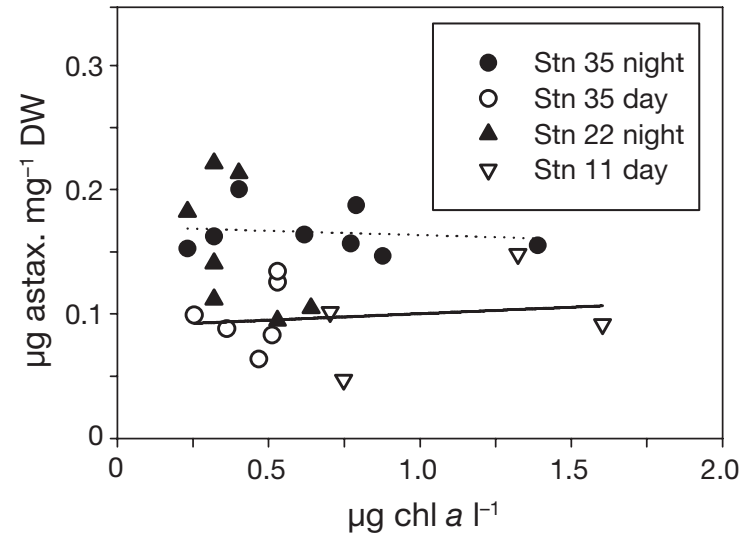

Fig. 2. Calanus helgolandicus. Total astaxanthin concentrations as a function of chl $a$. Dotted and continuous lines = least-square linear regressions $\left(r^{2}<0.05 ; p>0.7\right)$ for night and day, respectively

the concentrations of total astaxanthin were on average $60 \%$ higher at night than during the day. Multivariate analysis revealed that the difference between night and day concentrations was highly significant for both total and esterified astaxanthin, yet insignificant for free astaxanthin (Table 1). In turn, free astaxanthin were found to vary significantly with station; this was due to the combination of relatively low and high concentrations at Stns 11 and 35, respectively.

At Stn 35 (the only station sampled both day and night), the strongest diurnal differences $(\sim 0.04$ to $0.12 \mu \mathrm{g} \mathrm{mg}^{-1} \mathrm{DW}$ ) were found at the $8 \mathrm{~m}$ depth interval for all astaxanthin classes (Fig. 3). These differences correspond to increases of $\sim 180$ to $230 \%$ of the respective day concentrations. Overall, astaxanthin esters represented $\sim 60$ to $80 \%$ of the total astaxanthin concentration. At Stn 35, the degree of astaxanthin esterification was marginally higher during the day than at night within the upper ( $\geq 12 \mathrm{~m})$ water column, whereas the opposite was true for depths $>12 \mathrm{~m}$. Multivariate analysis detected no significant correlation of \% astaxanthin esters with depth, time or station (Table 1).

Table 1. Calanus helgolandicus. Results of multivariate analysis of astaxanthin concentrations and percent esterified astaxanthin using depth, time of sampling (day/night) and station as independent variables. Data were square root transformed to reduce heteroscedasticity. Statistically significant $(\mathrm{p}<0.05)$ results are in boldface

\begin{tabular}{|c|c|c|c|c|c|c|c|c|c|c|c|c|c|}
\hline \multirow{3}{*}{$\begin{array}{l}\text { Independent } \\
\text { variable }\end{array}$} & \multirow[t]{3}{*}{$\mathrm{df}$} & \multirow{2}{*}{\multicolumn{3}{|c|}{ Total astaxanthin }} & \multirow{2}{*}{\multicolumn{6}{|c|}{\begin{tabular}{ll} 
& \multicolumn{2}{c}{ Dependent variable } \\
Esterified astaxanthin $\quad$ Free astaxanthin
\end{tabular}}} & \multirow{2}{*}{\multicolumn{3}{|c|}{$\%$ esterified astaxanthin }} \\
\hline & & & & & & & & & & & & & \\
\hline & & MS & $F$ & $\mathrm{p}$ & MS & $F$ & $\mathrm{p}$ & MS & $F$ & $\mathrm{p}$ & MS & $F$ & $\mathrm{p}$ \\
\hline Depth & 1 & 0.01097 & 6.66 & 0.018 & 0.00748 & 6.77 & 0.017 & 0.19754 & 1.25 & $>0.3$ & 0.00049 & 0.08 & $>0.7$ \\
\hline Time (day/night) & 1 & 0.02155 & 13.08 & 0.002 & 0.03048 & 27.60 & $<0.0001$ & 0.11269 & 0.72 & $>0.4$ & 0.00075 & 0.12 & $>0.6$ \\
\hline Station & 2 & 0.00028 & 0.17 & $>0.8$ & 0.00238 & 2.15 & $>0.2$ & 0.72526 & 4.60 & 0.023 & 0.00053 & 0.09 & $>0.7$ \\
\hline
\end{tabular}




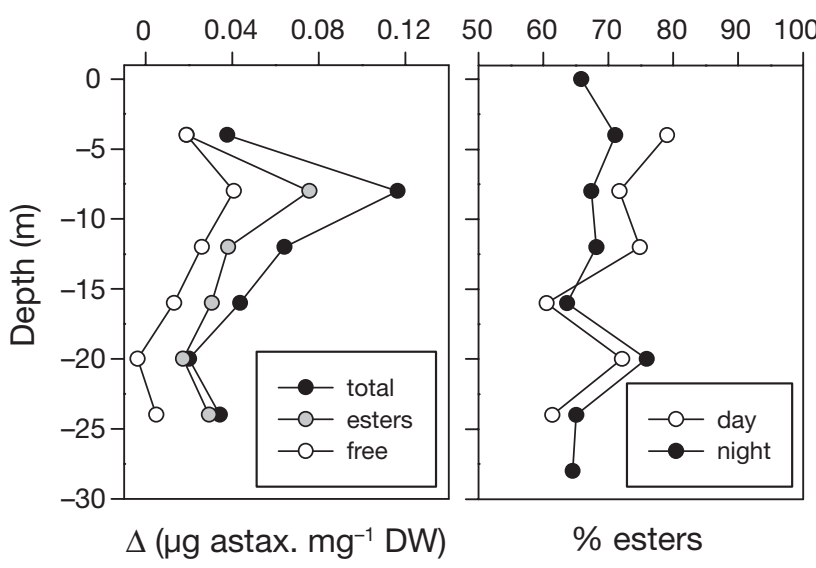

Fig. 3. Calanus helgolandicus. Diurnal (night/day) changes in astaxanthin concentrations and \% esters at Stn 35. Astaxanthin data shown only for 4 to $24 \mathrm{~m}$ depth interval, since daytime data lacking for surface and $28 \mathrm{~m}$ intervals

The initial samples of the onboard experiment, which were fixed immediately after sampling, contained $\sim 20$ to $70 \%$ higher astaxanthin concentrations (0.12 to $0.29 \mu \mathrm{g} \mathrm{mg}^{-1} \mathrm{DW}$, Fig. 4) than the field samples set aside for gut evacuation experiments. In treatments without food (Fig. 4: 'No food'), the concentrations of total astaxanthin decreased exponentially over time, both in the dark and (less pronounced) in the light. The concentrations of free astaxanthin decreased in both treatments by $\sim 40$ to $50 \%$ after 4 and $24 \mathrm{~h}$, respectively. In turn, the concentrations of esterified astaxanthin were sustained under light exposure, but decreased exponentially in the dark. Consequently, the degree of astaxanthin esterification at the end of the experiment was higher in starved individuals exposed to light $(\sim 73 \%)$ than those kept in the dark ( 67\%).

In treatments with water from the chl a maximum (Fig. 4: 'Food'), total astaxanthin concentrations decreased in the dark, but remained at approximately constant levels in the light. Free astaxanthin concentrations decreased exponentially over time, irrespective of the presence or absence of light, and thus resembled the pattern observed in the 'no food' treatments. In contrast, astaxanthin esters increased over time in individuals exposed to both food and light, while they were sustained at approximately initial levels in feeding individuals in the dark. The sustained levels of total astaxanthin in the light $\times$ food treatment were the result of a quantitatively similar $(\sim 0.06 \mu \mathrm{g}$ $\mathrm{mg}^{-1} \mathrm{DW}$ ) increase and decline in the esterified and free astaxanthin fraction, respectively. At the end of the experiment, the degree of esterification was on average slightly higher in feeding individuals exposed to light $(\sim 78 \%)$ than in those in the dark $(\sim 75 \%)$, although in both cases it was higher than in starved individuals ( 67 to $73 \%)$.

\section{DISCUSSION}

The most striking result of this study is that our sampling approach provided no conclusive picture of the factors governing the vertical distribution of astaxanthin in Calanus helgolandicus. This finding is in contrast to both our experimental results and previous field studies (Hairston 1980, Byron 1982, Hays et al. 1994, Hansson 2000), which demonstrated the important role of food and light on carotenoid pigmentation in zooplankton. Several reasons may account for this fact.

First, the use of chl a as an estimate of the potential ingestion of dietary carotenoids may be inadequate, since the composition of phytoplankton pigments (in particular the chl a:carotenoid ratio) may change with depth due to photochromatic adaptation (Berner et al. 1989). Further, grazing in copepods is frequently linked to diurnal rhythms such as nocturnal grazing rather than to food concentrations (Landry et al. 1994). We believe that the (on average) $60 \%$ higher astaxanthin concentrations found in the Calanus helgolandicus night samples are indicative of nocturnal grazing. This view is consistent with previous studies showing higher body carotenoid concentrations in zooplankton around midnight (Hallegraeff et al. 1978, Kleppel et al. 1985).

Most importantly, zooplankton vertical migration may explain the lack of any clear vertical pattern of astaxanthin concentrations in Calanus helgolandicus. Given the small-scale sensitivity of zooplankton survival to surface/UV irradiance (Zagarese et al. 1998), synthesis of photoprotective pigments may be expected to depend strongly on the time-integrated exposure to high-energy irradiance. Although previous studies have provided contrasting results on the vertical migratory behaviour of $C$. helgolandicus (Williams 1985, Gowen et al. 1997, Iriogoien et al. 2004), the fact that $C$. helgolandicus was consistently absent from surface samples during the day but present at night indicates that at least part of the population in our study was vertically migrating. It could be speculated that the absence of $C$. helgolandicus from the surface and the slightly higher astaxanthin concentrations in the $4 \mathrm{~m}$ depth interval during the day were the result of photoprotective behaviour/pigment synthesis. Diurnal descent of surface individuals to intermediate depths also seems a likelier reason for the elevated diurnal changes of astaxanthin in the $8 \mathrm{~m}$ depth interval than selective predation by visual predators. Comparison of astaxanthin concentrations in C. hel-

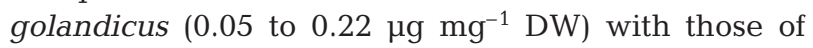
conspicuously coloured copepods in ponds and rock pools ( 2 to $10 \mu \mathrm{g} \mathrm{mg}^{-1} \mathrm{DW}$; Hairston 1978, Hessen \& Sørensen 1990, Davenport et al. 2004), indicates that the range of astaxanthin concentrations in C. hel- 

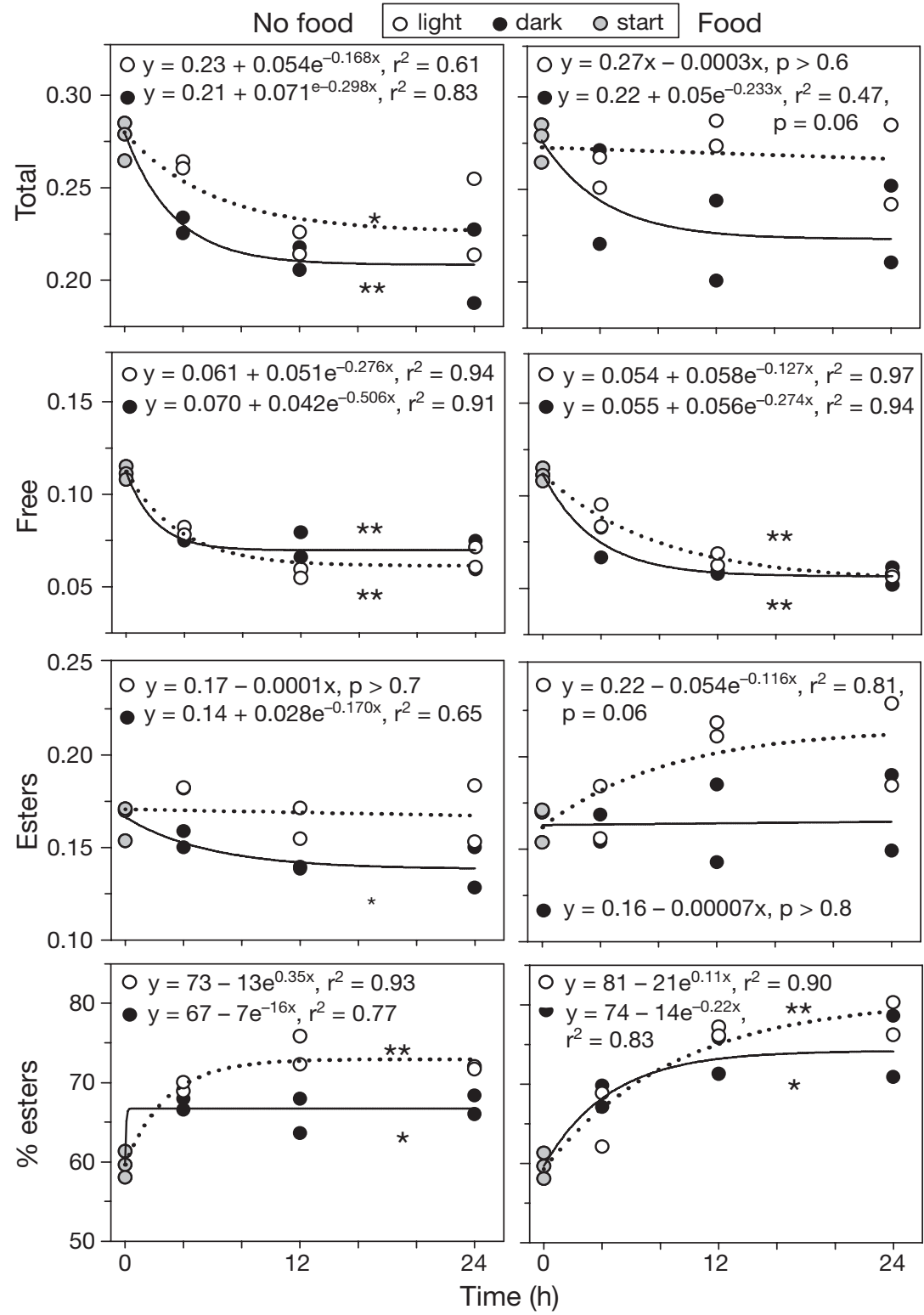

Fig. 4. Calanus helgolandicus. Astaxanthin $\left(\mu \mathrm{g} \mathrm{mg}{ }^{-1} \mathrm{DW}\right)$ dynamics in the $2 \times 2$ factorial (food $\times$ light) experiment. No food, Food $=$ treatments with unfiltered seawater from chl a maximum and GF/F-filtered seawater, respectively. Dotted and continuous lines $=$ least-square regressions for treatments with and without light exposure, respectively. ${ }^{*} \mathrm{p}<0.05,{ }^{* *} \mathrm{p}<0.005$

golandicus is unlikely to produce predation-relevant differences in visual conspicuousness, given the generally turbid conditions of the North Sea.

The results of the $2 \times 2$ factorial experiment showed that astaxanthin production is a dynamic and rapid process. As reported in a previous study for the congeneric species Calanus pacificus (Juhl et al. 1996), astaxanthin degradation rates in C. helgolandicus may be particularly pronounced in starved individuals ( 30 to $\left.50 \% \mathrm{~d}^{-1}\right)$. Thus, the prolonged handling time $(\sim 4 \mathrm{~h})$ in our depth-profile experiment inevitably resulted in the underestimation of $C$. helgolandicus astaxanthin concentrations. This is probably also the reason why the initial samples of the onboard experiment, which were fixed immediately after sampling, had $\sim 20$ to $70 \%$ higher astaxanthin concentrations than the field samples.

A more important result, however, was that the total astaxanthin concentrations were entirely determined by the dynamics of esterified astaxanthin. While the presence of food allowed copepods to maintain their initial level of esterified astaxanthin, the combined effect of food and light was to increase the concentration of astaxanthin esters. This was surprising, since newly synthesised astaxanthin may be expected to first become apparent as unesterified pigment. The reason for the decline of free astaxanthin in all treatments is unknown, but may be related to the experimental design. Our use of white fluorescent lamps exposed the copepods to a qualitatively different light regime than they experience in the field, including a significant portion of blue light that is absent at the depth $(\sim 42 \mathrm{~m})$ of the chl a maximum (Jerlov 1976). Thus, it is possible that newly synthesised free astaxanthin was rapidly esterified as a specific response to the blue fraction of the emission spectrum. We may similarly speculate that the somewhat higher degree of astaxanthin esterification in the upper $(\leq 12 \mathrm{~m}$ ) water column during the day at Stn 35 was the result of a photoprotective response to high-energy irradiance (possibly, blue light).

However, the fact that the presence of food allowed copepods to sustain the levels of astaxanthin esters in treatments without light implies that astaxanthin esterification is per se a process independent of light. Similary, other investigators have found that astaxanthin is deposited mainly as esters and not free astaxanthin in many crustaceans, particularly during ontogenetic development (Yamada et al. 1990, Petit et al. 1991, Dall et al. 1995), resulting in the predominance ( 60 to $90 \%$ ) of astaxanthin esters in the adults of many crustaceans (Yamaguchi et al. 1983, Coral-Hinostroza \& Bjerkeng 2002) including calanoid copepods (Foss et al. 1987, Juhl et al. 1996, Andersson et al. 2003, 
Lotocka et al. 2004). Since the esterification of astaxanthin with fatty acids makes the pigment increasingly lipophilic (Kobayashi \& Sakamoto 1999), the potential function of astaxanthin esters may be to improve the deposition and thus protection of storage lipids. This may be advantageous also in conditions when light is absent, e.g. during periods of diapause in deeper water layers, since reactive oxygen species responsible for lipid peroxidation are produced also during normal oxidative processes (Davies 1995).

In conclusion, we propose that the commonly accepted notion of a photoprotective role of astaxanthin, particularly against biologically harmful UV irradiance (Kouwenburg et al. 1999), needs to be refined. Although our results demonstrate that astaxanthin concentrations increase under light exposure, we suggest that photoprotection may represent but one case of a general beneficial antioxidant function of astaxanthin. The observation that copepods avoid surface waters during the daytime (Alonso et al. 2004, present study) and the occurrence of higher astaxanthin concentrations at night, when photoprotection is unnecessary, support this view.

Acknowledgements. We thank the crew and staff of the RVs 'Alkor' and 'Dana', and especially J. Renz, R. Voss and A. Visser for help during field work. Help with HPLC and statistical analysis by W. Martinsen and C. Simonson is acknowledged. F.S. thanks GLOBEC-Germany for the possibility of cruise participation. This study was financially supported by grants to F.S. (Schrödinger-grant J2370-B03, Austrian Science Foundation), C.A. (A-0216469, German Academic Exchange Service DAAD) and T.K. (Danish Natural Science Research Council).

\section{LITERATURE CITED}

Alonso C, Rocco V, Barriga JP, Battini MA, Zagarese H (2004) Surface avoidance by freshwater zooplankton: field evidence on the role of ultraviolet radiation. Limnol Oceanogr 49:225-232

Andersson M, Van Nieuwerburgh L, Snoeijs P (2003) Pigment transfer from phytoplankton to zooplankton with emphasis on astaxanthin production in the Baltic Sea food web. Mar Ecol Prog Ser 254:213-224

Berner T, Dubinsky Z, Wyman K, Falkowski PG (1989) Photoadaptation and the 'package' effect in Dunaliella tetriolecta (Cholorphyceae). J Phycol 25:70-78

Byron ER (1982) The adaptive significance of calanoid copepod pigmentation: a comparative and experimental analysis. Ecology 63:1871-1886

Coral-Hinostroza GN, Bjerkeng B (2002) Astaxanthin from the red crab langostilla (Pleuroncodes planipes): optical $\mathrm{R} / \mathrm{S}$ isomers and fatty acid moieties of astaxanthin esters. Comp Biochem Physiol B 133:437-444

Dall W, Smith DM, Moore LE (1995) Carotenoids in the tiger prawn Penaeus esculentus during ovarian maturation. Mar Biol 123:435-441

Davenport J, Healy A, Casey N, Heffron JJA (2004) Dietdependent UVAR and UVBR resistance in the high shore harpacticoid copepod Tigriopus brevicornis. Mar Ecol Prog Ser 276:299-303

Davies KJA (1995) Oxidative stress: the paradox of life. Biochem Soc Symp 61:273

Foss P, Renstrøm B, Liaaen-Jensen S (1987) Natural occurrence of enantiomeric and meso astaxanthin $7^{*}-$ crustaceans including zooplankton. Comp Biochem Physiol B 86:313-134

Goodwin TW (1984) The biochemistry of the carotenoids, Vol II. Animals. Chapman \& Hall, New York

Gowen, RJ, Dickey-Collas M, McCullough G (1997) The occurrence of Calanus finmarchicus (Gunnerus) and Calanus helgolandicus (Claus) in the western Irish Sea. J Plankton Res 19:1175-1182

Hairston NG (1978) Carotenoid photoprotection in Diaptomus kenai. Verh Int Ver Theor Angew Limnol 20:2541-2545

Hairston NG (1979) The adaptive significance of color polymorphism in two species of Diaptomus (Copepoda). Limnol Oceanogr 24:15-37

Hairston NG (1980) The vertical distribution of diaptomid copepods in relation to body pigmentation. In: Kerfoot WC (ed) Evolution and ecology of zooplankton communities, University Press, Hanover, NH, p 98-110

Hallegraeff GM, Mous IJ, Veeger R, Flik BJG, Ringelberg J (1978) A comparative study on the carotenoid pigmentation of the zooplankton of Lake Maarsseveen (Netherlands) and of Lac Pavin (Auvergne, France) II. Diurnal variations in carotenoid content. Comp Biochem Physiol 60:59-62

Hansson LA (2000) Induced pigmentation in zooplankton: a trade-off between threats from predation and ultraviolet radiation. Proc R Soc Lond B 267:2327-2331

Hays GC, Proctor CA, John WG, Warner AJ (1994) Interspecific differences in the diel vertical migration of marine copepods: the implications of size, color, and morphology. Limnol Oceanogr 39:1621-1629

Herring PJ (1972) Depth distribution of the carotenoid pigments and lipids of some oceanic animals. 1. Mixed zooplankton, copepods and euphausiids. J Mar Biol Assoc UK 52:179-189

Hessen DO, Sørensen K (1990) Photoprotective pigmentation in alpine zooplankton populations. Aqua Fenn 20:165-170

Irigoien X, Conway DVP, Harris RP (2004) Flexible diel vertical migration behaviour of zooplankton in the Irish Sea. Mar Ecol Prog Ser 267:85-97

Jerlov NG (1976) Marine optics. Elsevier, Amsterdam

Juhl AR, Ohman MD, Goericke R (1996) Astaxanthin in Calanus pacificus: an assessment of pigment-based measures of omnivory. Limnol Oceanogr 41:1198-1207

Kleppel GS, Willbanks L, Pieper RE (1985) Diel variation in body carotenoid content and feeding activity in marine zooplankton assemblages. J Plankton Res 7:569-580

Kobayashi M, Sakamoto Y (1999) Singlet oxygen quenching ability of astaxanthin esters from the green alga Haematococcus pluvialis. Biotechnol Lett 21:265-269

Kouwenberg JHM, Browman HI, Runge JA, Cullen JJ, Davis RF, St-Pierre JF (1999) Biological weighting of ultraviolet $(280-400 \mathrm{~nm})$ induced mortality in marine zooplankton and fish. II. Calanus finmarchicus (Copepoda) eggs. Mar Biol 134:285-293

Kuhn P, Browman HI, McArthur B, St-Pierre JF (1999) Penetration of ultraviolet radiation in the waters of the estuary and Gulf of St. Lawrence. Limnol Oceanogr 44:710-716

Landry MR, Peterson WK, Fagerness VL (1994) Mesozooplankton grazing in the Southern California Bight. I. Population abundances and gut pigment contents. Mar Ecol Prog Ser 115:55-71 
Lotocka M, Styczynska-Jurewicz E, Bledzki LA (2004) Changes in carotenoid composition in different developmental stages of copepods: Pseudocalanus acuspes Giesbrecht and Acartia spp. J Plankton Res 26:159-166

Luecke C, O'Brien WJ (1981) Phototoxicity and fish predation: selective factors in color morphs in Heterocope. Limnol Oceanogr 26:454-460

Mauchline J (1998) The biology of calanoid copepods. Adv Mar Biol 33:1-710

Petit H, Sance S, Negre-Sadargues C, Castillo R, Trilles JP (1991) Ontogeny of carotenoid metabolism in the prawn Penaeus japonicus Bate (1888) (Crustacea Penaeidea). A qualitative approach. Comp Biochem Physiol B 99:667-671

Rhode SC, Pawlowski M, Tollrian R (2001) The impact of ultraviolet radiation on the vertical distribution of zooplankton of the genus Daphnia. Nature 412:69-71

Ringelberg J, Keyser AL, Flik BJG (1984) The mortality effect of ultraviolet radiation in a translucent and in a red morph

Editorial responsibility: Otto Kinne (Editor-in-Chief), Oldendorf/Luhe, Germany of Acanthodiaptomus denticornis (Crustacea, Copepoda) and its possible ecological relevance. Hydrobiologia 112: $217-222$

Williams R (1985) Vertical distribution of Calanus finmarchicus and C. helgolandicus in relation to the development of the seasonal thermocline in the Celtic Sea. Mar Biol 86: 145-149

Yamada S, Tanaka Y, Sameshikma M, Ito Y (1990) Pigmentation of prawn (Penaeus japonicus) with dietary carotenoids. I. Effect of dietary astaxanthin, $\beta$-carotene and canthaxanthin on pigmentation. Aquaculture 87: $323-330$

Yamaguchi K, Miki W, Toriu N, Kondo Y, Murakami M, Konosu S, Stake M, Fujita T (1983) The composition of carotenoid pigments in the Antarctic krill Euphausia superba. Bull Jpn Soc Sci Fish 49:1411-1415

Zagarese HE, Tartarotti B, Cravero W, Gonzalez P (1998) UV damage in shallow lakes: the implications of water mixing. J Plankton Res 20:1423-1433

Submitted: May 23, 2005; Accepted: January 10, 2006

Proofs received from author(s): July 28. 2006 